Supplement of Hydrol. Earth Syst. Sci. Discuss., 12, 10789-10825, 2015

http://www.hydrol-earth-syst-sci-discuss.net/12/10789/2015/

doi:10.5194/hessd-12-10789-2015-supplement

(C) Author(s) 2015. CC Attribution 3.0 License.

(c) (i)

\title{
Modelling evapotranspiration during precipitation deficits: identifying critical processes in a land surface model
}

\section{A. M. Ukkola et al.}

Correspondence to: A. M. Ukkola (amukkola@gmail.com)

The copyright of individual parts of the supplement might differ from the CC-BY 3.0 licence. 
Table S1. Study flux tower sites. PFT stands for plant functional type.

\begin{tabular}{|c|c|c|c|c|c|}
\hline Site name & Country & Lat. & Long. & CABLE PFT & $\begin{array}{l}\text { Record } \\
\text { length }\end{array}$ \\
\hline Amplero* & Italy & 41.90 & 13.61 & $\mathrm{C}_{3}$ grass & 2003-2006 \\
\hline Blodgett ${ }^{*}$ & USA & 38.90 & -120.63 & Evergreen needleleaf & $2000-2006$ \\
\hline Bugac & Hungary & 46.69 & 19.60 & $\mathrm{C}_{3}$ grass & 2002-2006 \\
\hline El Saler & Spain & 39.35 & -0.32 & Evergreen needleleaf & 2003-2005 \\
\hline EI Saler 2 & Spain & 39.28 & -0.32 & $\mathrm{C}_{3}$ crop & $2005-2006$ \\
\hline Espirra & Portugal & 38.64 & -8.60 & Evergreen broadleaf & $2001-2006$ \\
\hline Fort Peck & USA & 48.31 & -105.10 & $\mathrm{C}_{3}$ grass & $2000-2006$ \\
\hline Harvard & USA & 42.54 & -72.17 & Deciduous broadleaf & $1994-2001$ \\
\hline Hesse & France & 48.67 & 7.06 & Deciduous broadleaf & 1999-2006 \\
\hline Howard Springs* & Australia & -12.49 & 131.15 & $\mathrm{C}_{4}$ grass & $2002-2005$ \\
\hline Howland main & USA & 45.20 & -68.74 & Evergreen needleleaf & 1996-2004 \\
\hline Hyytiälä & Finland & 61.85 & 24.29 & Evergreen needleleaf & 2001-2004 \\
\hline Kruger & South Africa & -25.02 & 31.50 & $\mathrm{C}_{4}$ grass & $2002-2003$ \\
\hline Loobos & Netherlands & 52.17 & 5.74 & Evergreen needleleaf & $1997-2006$ \\
\hline Merbleue & Canada & 45.41 & -75.52 & Wetland & $1999-2005$ \\
\hline Mopane & Botswana & -19.92 & 23.56 & $\mathrm{C}_{4}$ grass & $1999-2001$ \\
\hline Palang* & Indonesia & 2.35 & 111.04 & Evergreen broadleaf & $2002-2003$ \\
\hline Sylvania & USA & 46.24 & -89.35 & Deciduous broadleaf & $2002-2005$ \\
\hline Tumbarumba* & Australia & -35.66 & 148.15 & Evergreen broadleaf & $2002-2005$ \\
\hline $\begin{array}{l}\text { University of } \\
\text { Michigan* }\end{array}$ & USA & 45.56 & -84.71 & Deciduous broadleaf & $1999-2003$ \\
\hline
\end{tabular}

${ }^{*}$ Selected site 
Table S2. Parameter values for the three soil classes used to run CABLE. "Default" and "new" refer to the two hydrological schemes employed in the study. Where only one value is given, both schemes use an identical value for the parameter.

\begin{tabular}{|c|c|c|c|c|c|c|}
\hline Parameter & \multicolumn{2}{|c|}{ Sand } & \multicolumn{2}{|c|}{ Medium } & \multicolumn{2}{|c|}{ Clay } \\
\hline Silt content (fraction) & \multicolumn{2}{|c|}{0.08} & \multicolumn{2}{|c|}{34} & \multicolumn{2}{|c|}{0.17} \\
\hline Clay content (fraction) & \multicolumn{2}{|c|}{0.09} & \multicolumn{2}{|c|}{33} & \multicolumn{2}{|c|}{0.67} \\
\hline Sand content (fraction) & \multicolumn{2}{|c|}{0.83} & \multicolumn{2}{|c|}{33} & \multicolumn{2}{|c|}{0.16} \\
\hline Soil density $\left(\mathrm{kg} / \mathrm{m}^{3}\right)$ & \multicolumn{2}{|c|}{1600} & \multicolumn{2}{|c|}{1490} & \multicolumn{2}{|c|}{1381} \\
\hline \multirow[t]{2}{*}{ Soil heat capacity $(\mathrm{J} / \mathrm{kg} / \mathrm{C})$} & \multicolumn{2}{|c|}{850} & \multicolumn{2}{|c|}{850} & \multicolumn{2}{|c|}{850} \\
\hline & Default & New & Default & New & Default & New \\
\hline $\begin{array}{l}\text { Volumetric water content at } \\
\text { wilting }\left(\mathrm{m}^{3} / \mathrm{m}^{3}\right)\end{array}$ & 0.072 & 0.034 & 0.179 & 0.149 & 0.286 & 0.251 \\
\hline $\begin{array}{l}\text { Volumetric water content at } \\
\text { field capacity }\left(\mathrm{m}^{3} / \mathrm{m}^{3}\right)\end{array}$ & 0.142 & 0.168 & 0.255 & 0.298 & 0.367 & 0.369 \\
\hline $\begin{array}{l}\text { Volumetric water content at } \\
\text { saturation }\left(\mathrm{m}^{3} / \mathrm{m}^{3}\right)\end{array}$ & 0.398 & 0.384 & 0.440 & 0.447 & 0.482 & 0.469 \\
\hline $\begin{array}{l}\text { Parameter B (Clapp and } \\
\text { Hornberger, 1978) }\end{array}$ & 4.20 & 4.34 & 7.80 & 8.12 & 11.4 & 13.6 \\
\hline $\begin{array}{l}\text { Hydraulic conductivity at } \\
\text { saturation }(\mathrm{m} / \mathrm{s})\end{array}$ & $166 \times 10^{-6}$ & $17 \times 10^{-6}$ & $83 \times 10^{-6}$ & $2.9 \times 10^{-6}$ & $1 \times 10^{-6}$ & $2 \times 10^{-6}$ \\
\hline Suction at saturation $(\mathrm{m})$ & -0.106 & -0.062 & -0.255 & -0.280 & -0.405 & -0.468 \\
\hline
\end{tabular}




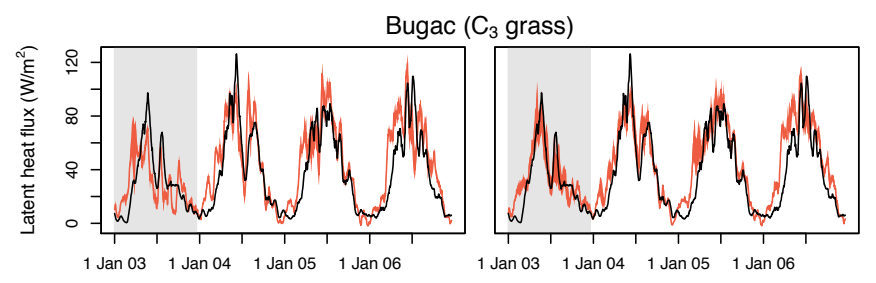

EISaler (Ev needle)

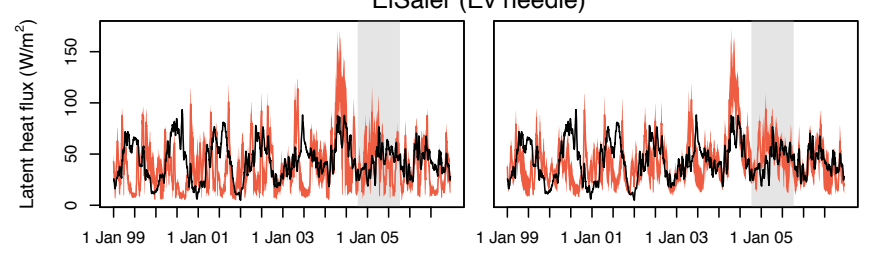

El Saler $2\left(\mathrm{C}_{3}\right.$ crop)

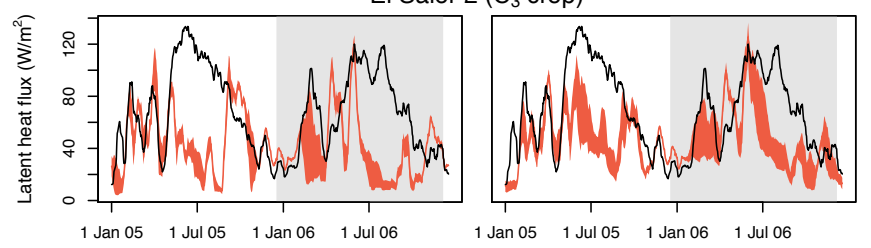

Espirra (Ev broad)

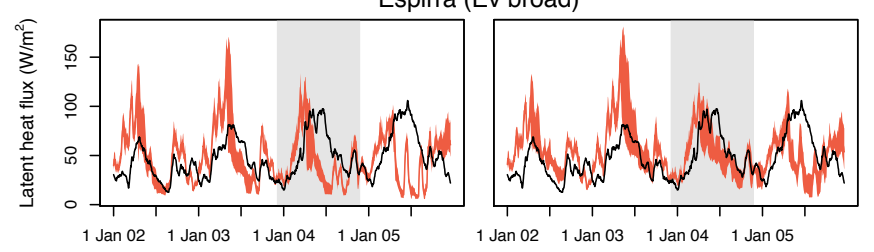

Fort Peck $\left(\mathrm{C}_{3}\right.$ grass $)$

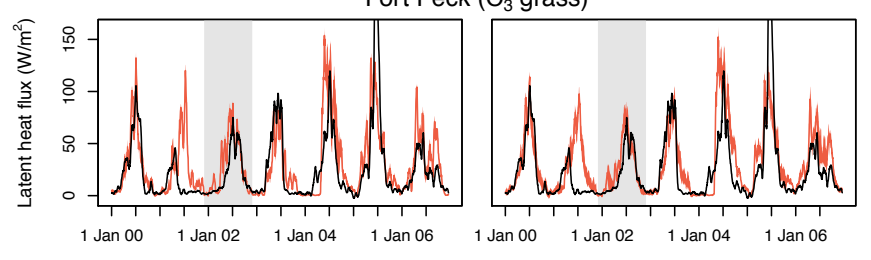

Harvard (Dec broad)

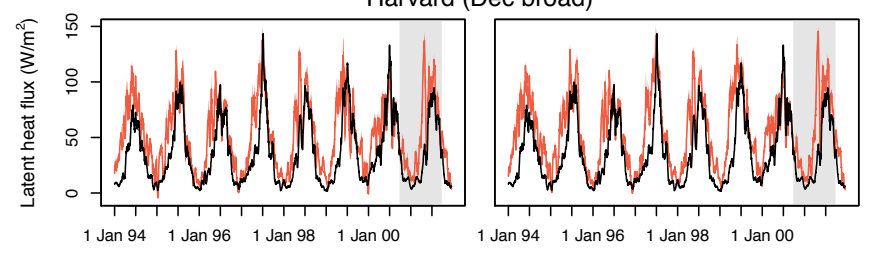

Hesse (Dec broad)

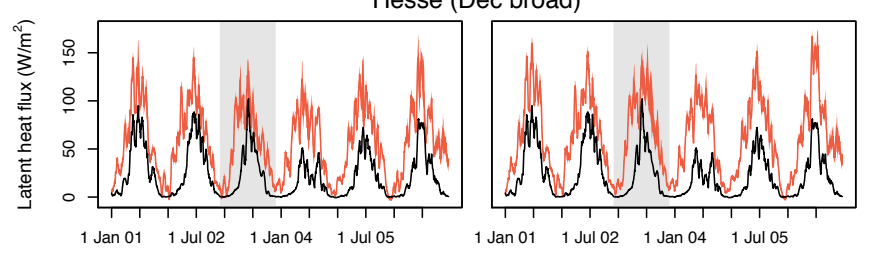

Fig. S1. The range in simulated latent heat (red) during the whole observational data period using the default (left panel) and new (right panel) hydrological schemes with alternative LAl, $g_{s}$ and soil parameterisations. Observed latent heat is shown in black. The grey shading denotes the year of lowest precipitation. 

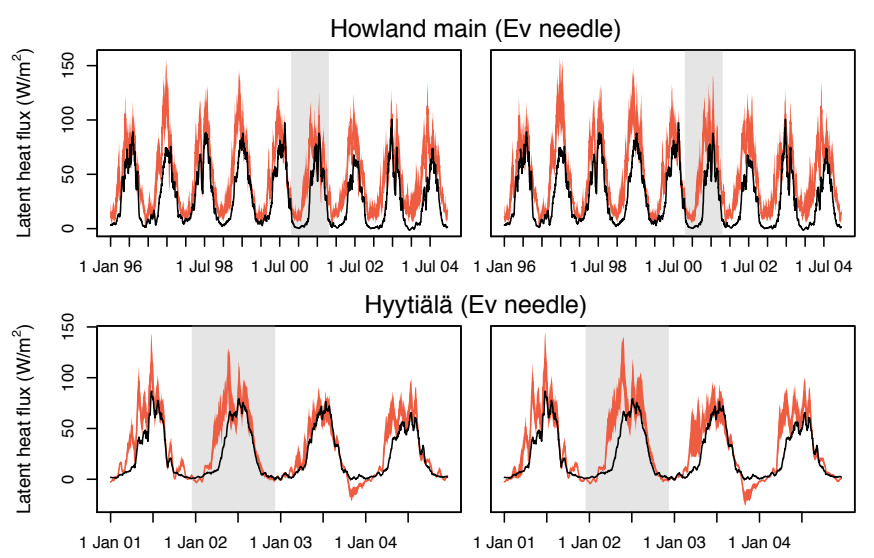

Kruger $\left(\mathrm{C}_{4}\right.$ grass $)$

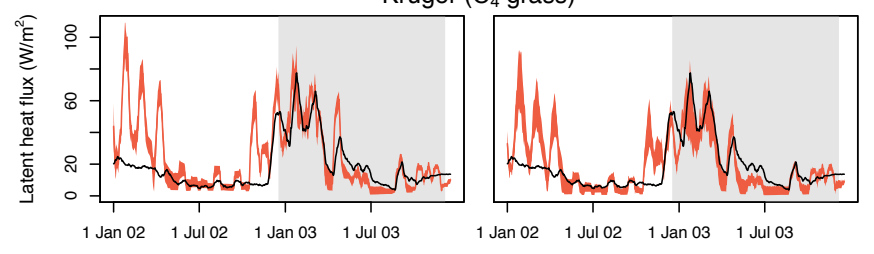

Loobos (Ev needle)

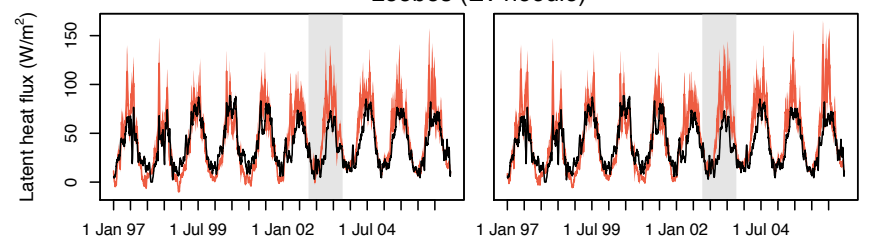

Merbleue (Wetland)

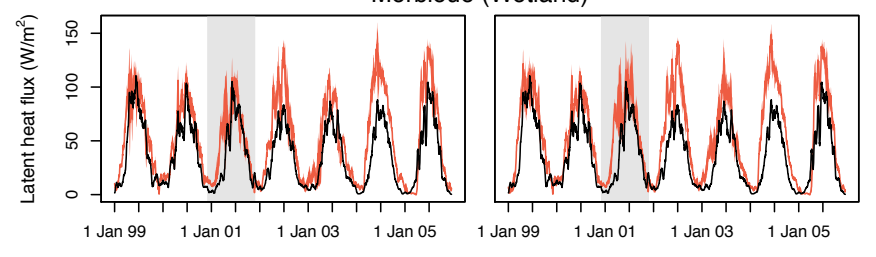

Mopane $\left(\mathrm{C}_{4}\right.$ grass $)$

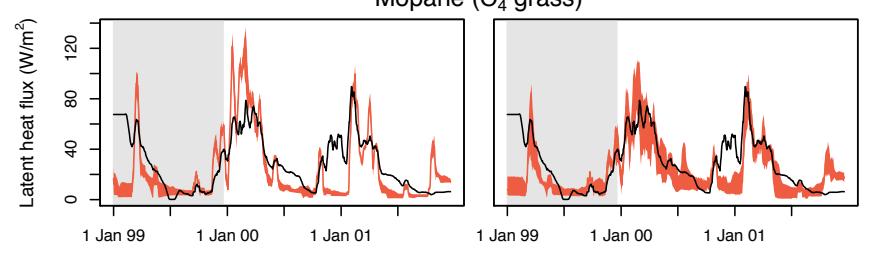

Sylvania (Dec broad)

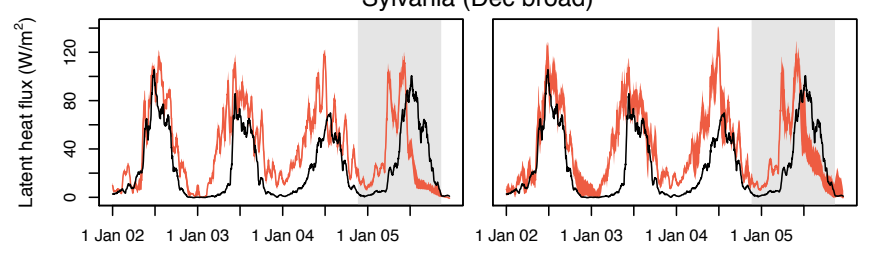

Fig. S1 continued. 

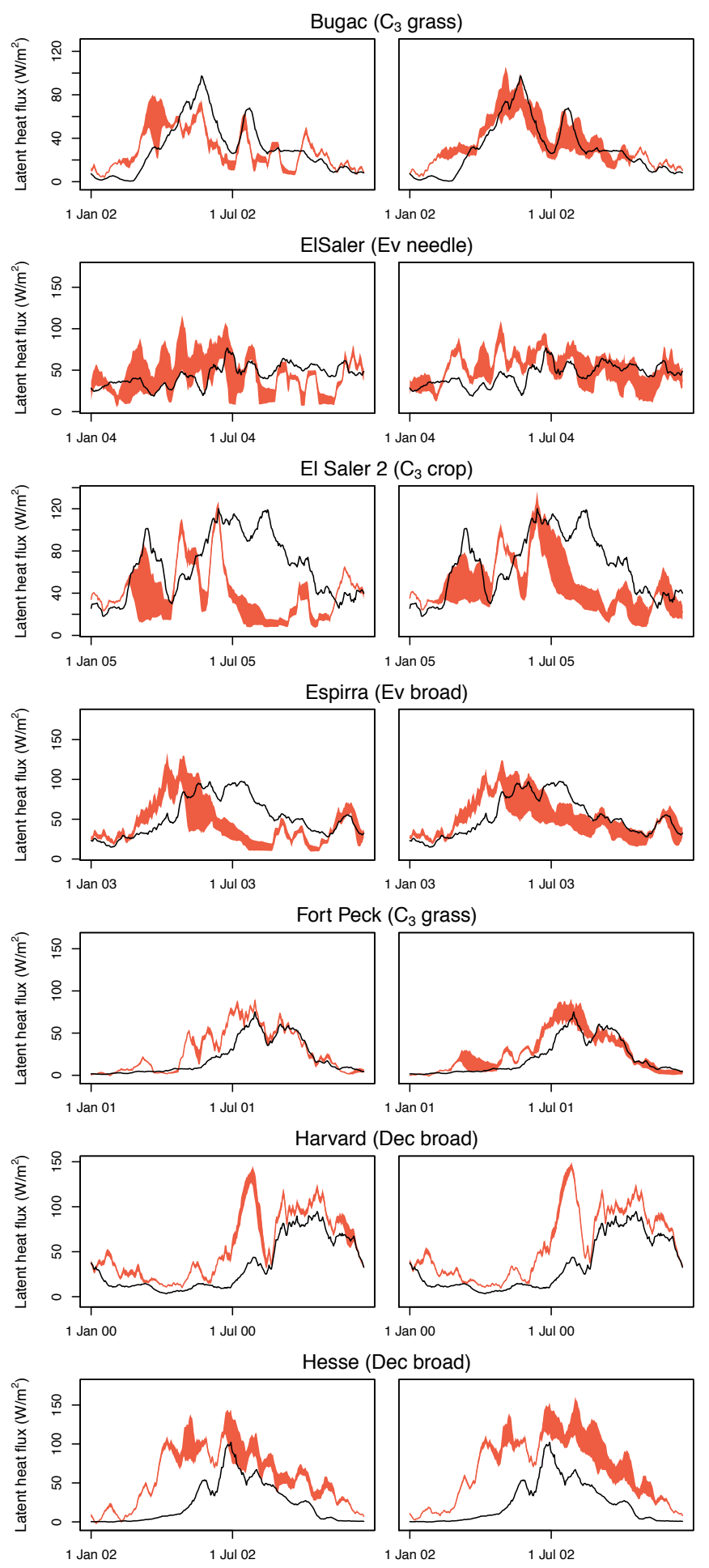

Fig. S2. The range in simulated latent heat (red) during the year of lowest precipitation using the default (left panel) and new (right panel) hydrological schemes with alternative LAI, $g_{s}$ and soil parameterisations. Observed latent heat is shown in black. 

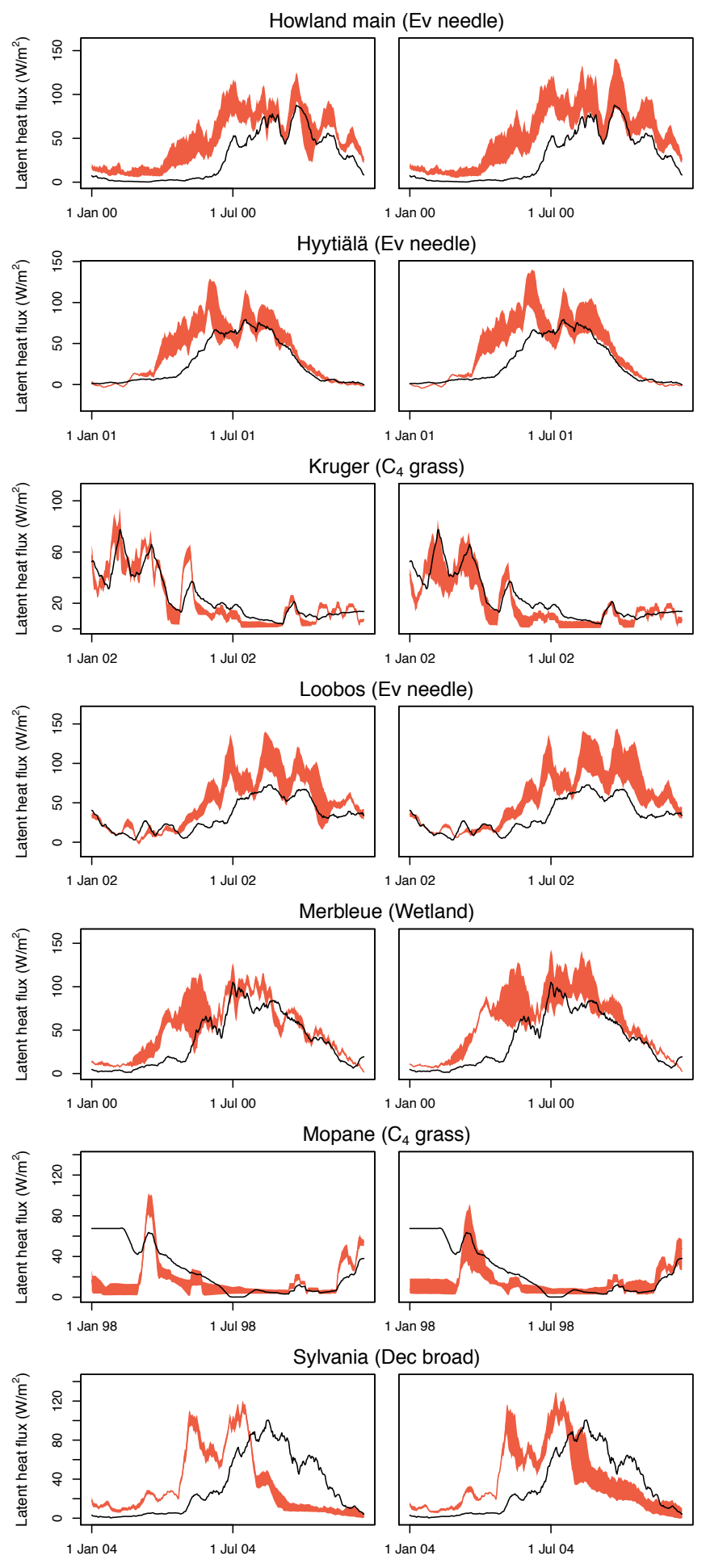

Fig. S2 continued. 

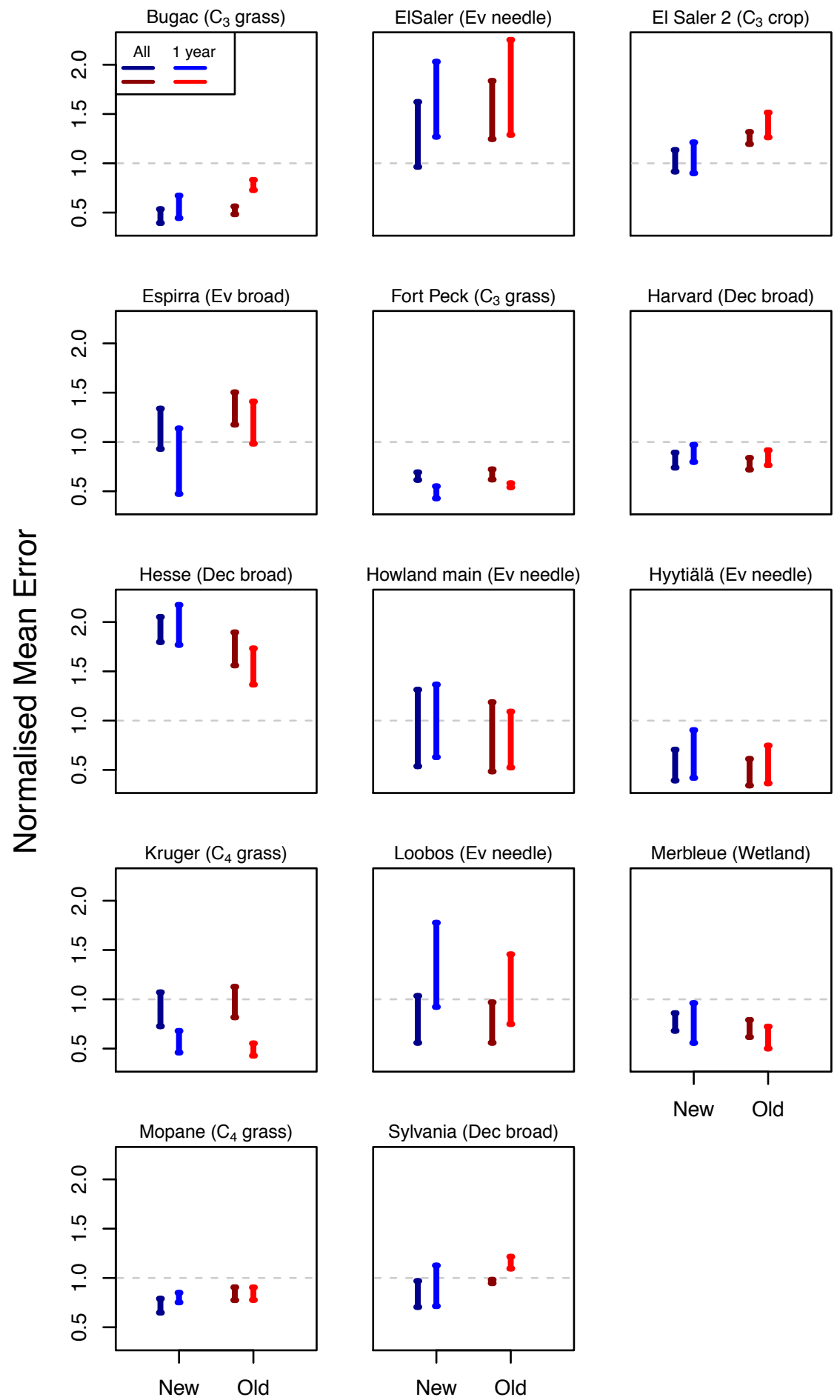

Fig. S3. The range in normalised mean error metrics of latent heat simulations using the default (red) and new (blue) hydrological schemes with alternative LAI, $g_{s}$ and soil parameterisations during the whole data period and the year of lowest precipitation. The new scheme was run with $0^{\circ}$ slope. 

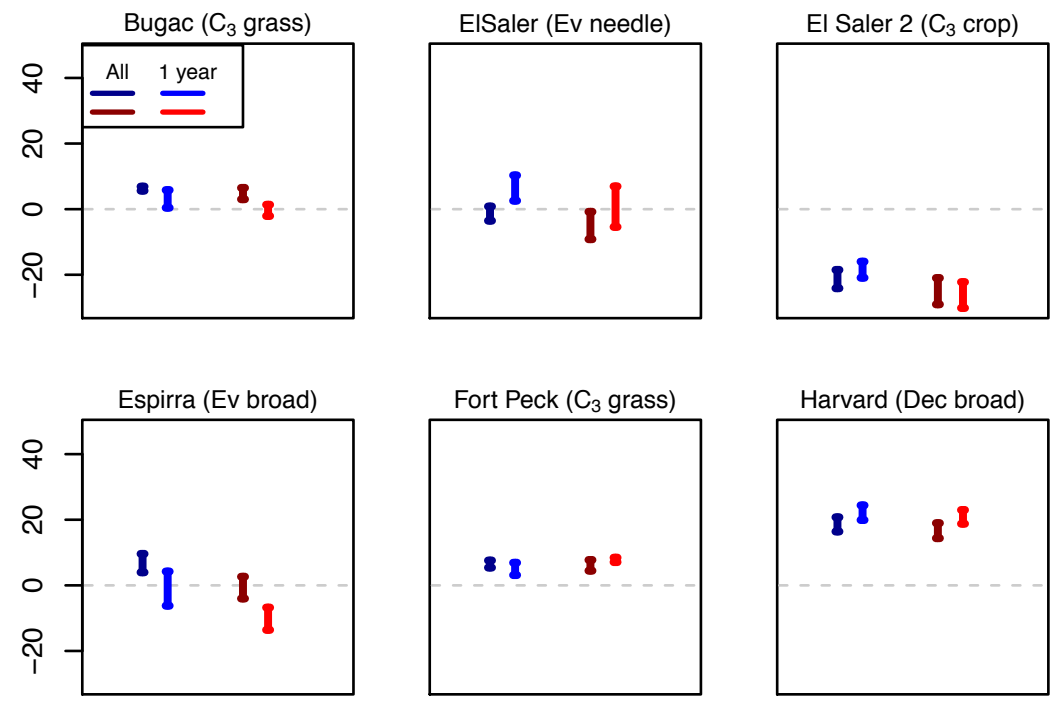

롱
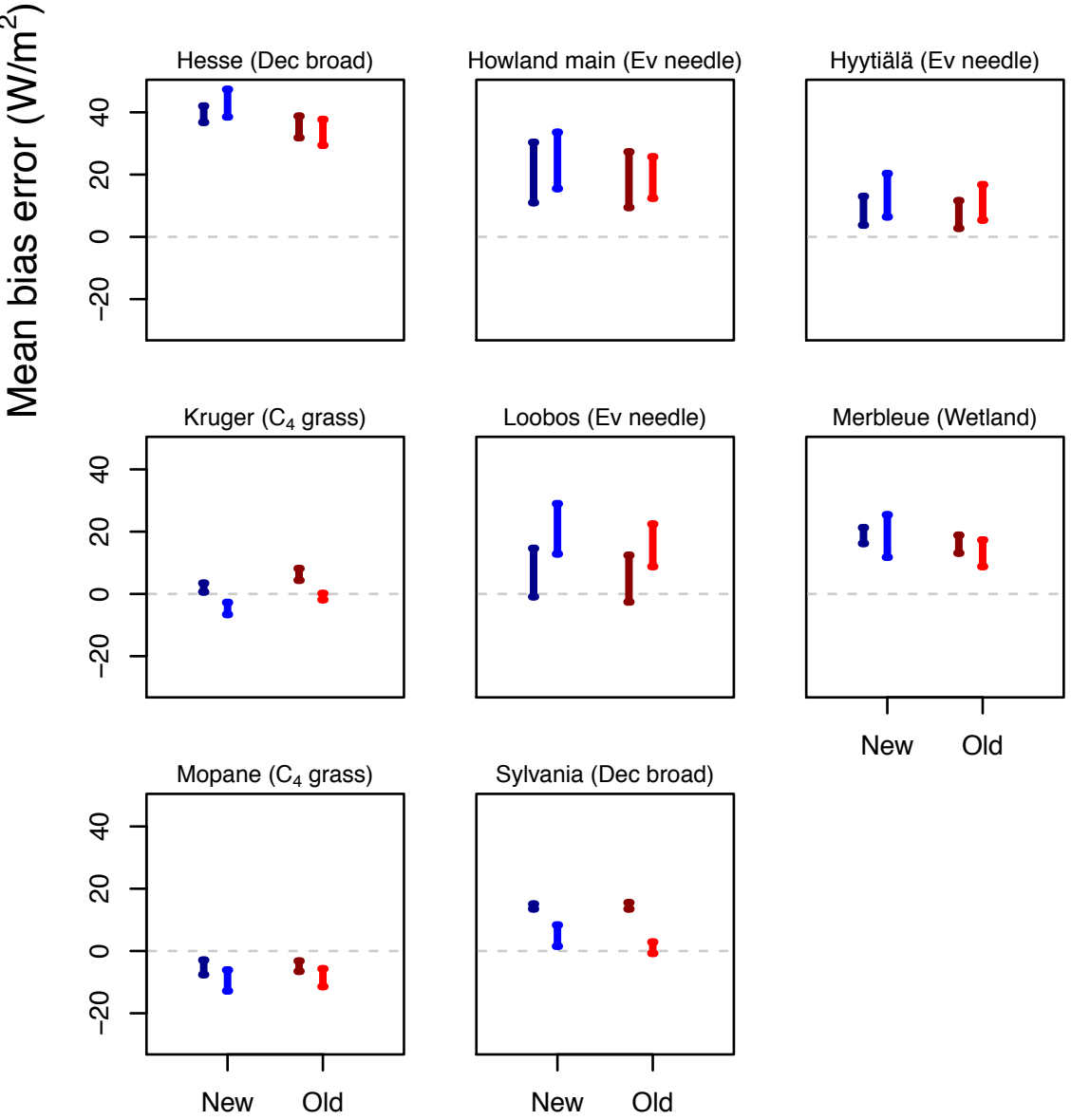

Fig. S4. The range in mean bias error metrics of latent heat simulations using the default (red) and new (blue) hydrological schemes with alternative LAI, $g_{s}$ and soil parameterisations during the whole, annual and dry-down periods. The new scheme was run with $0^{\circ}$ slope. 


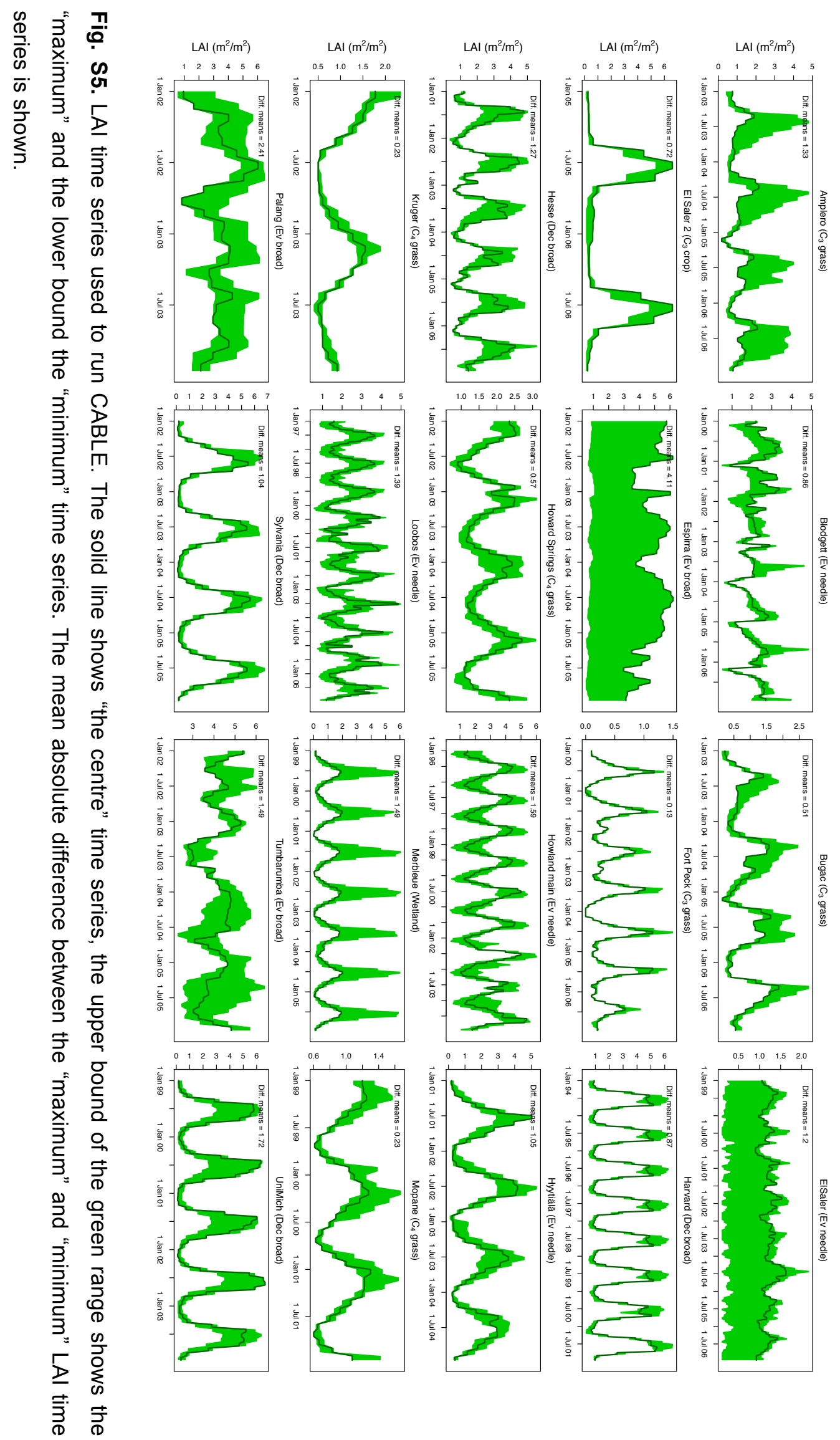




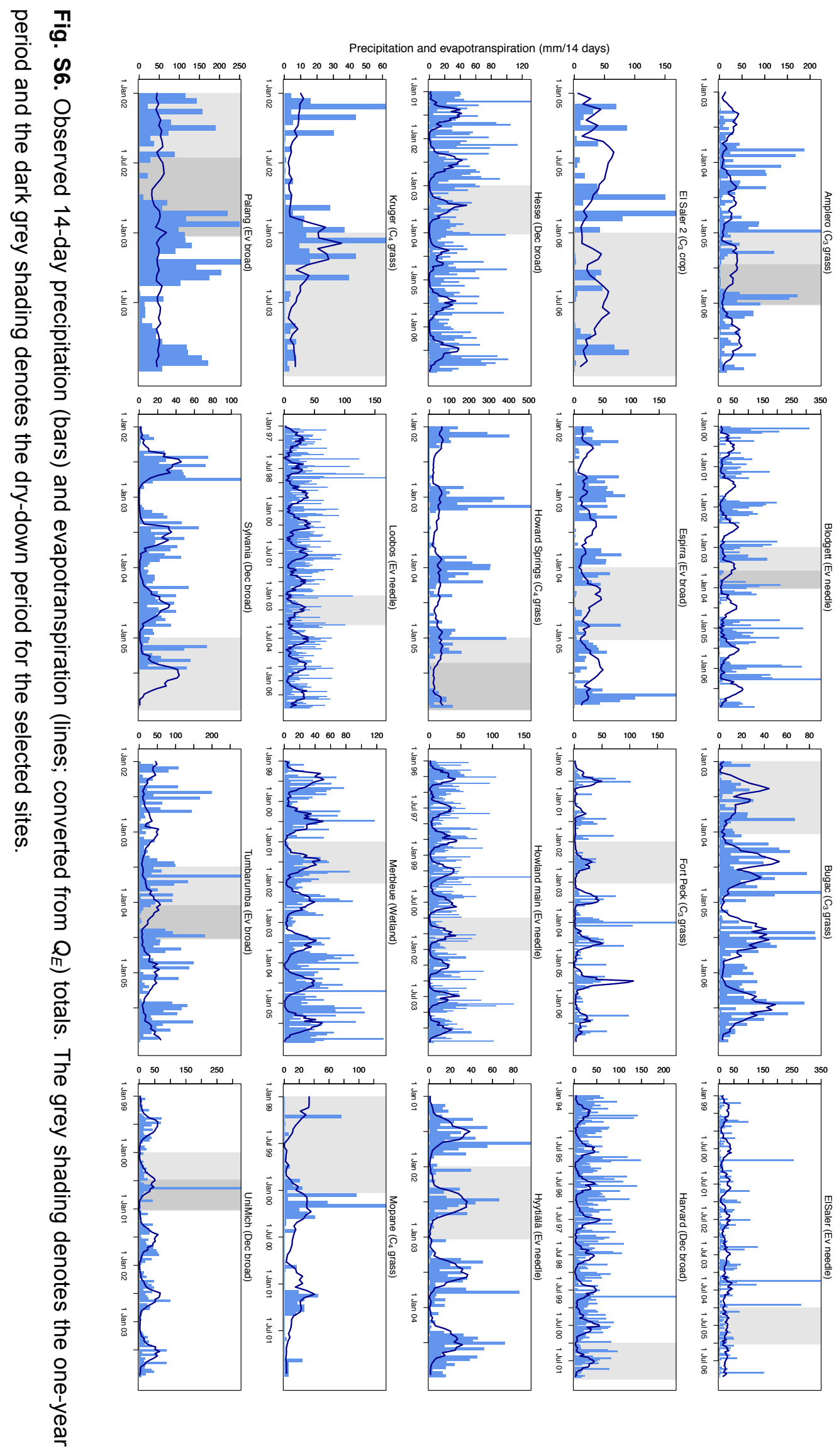



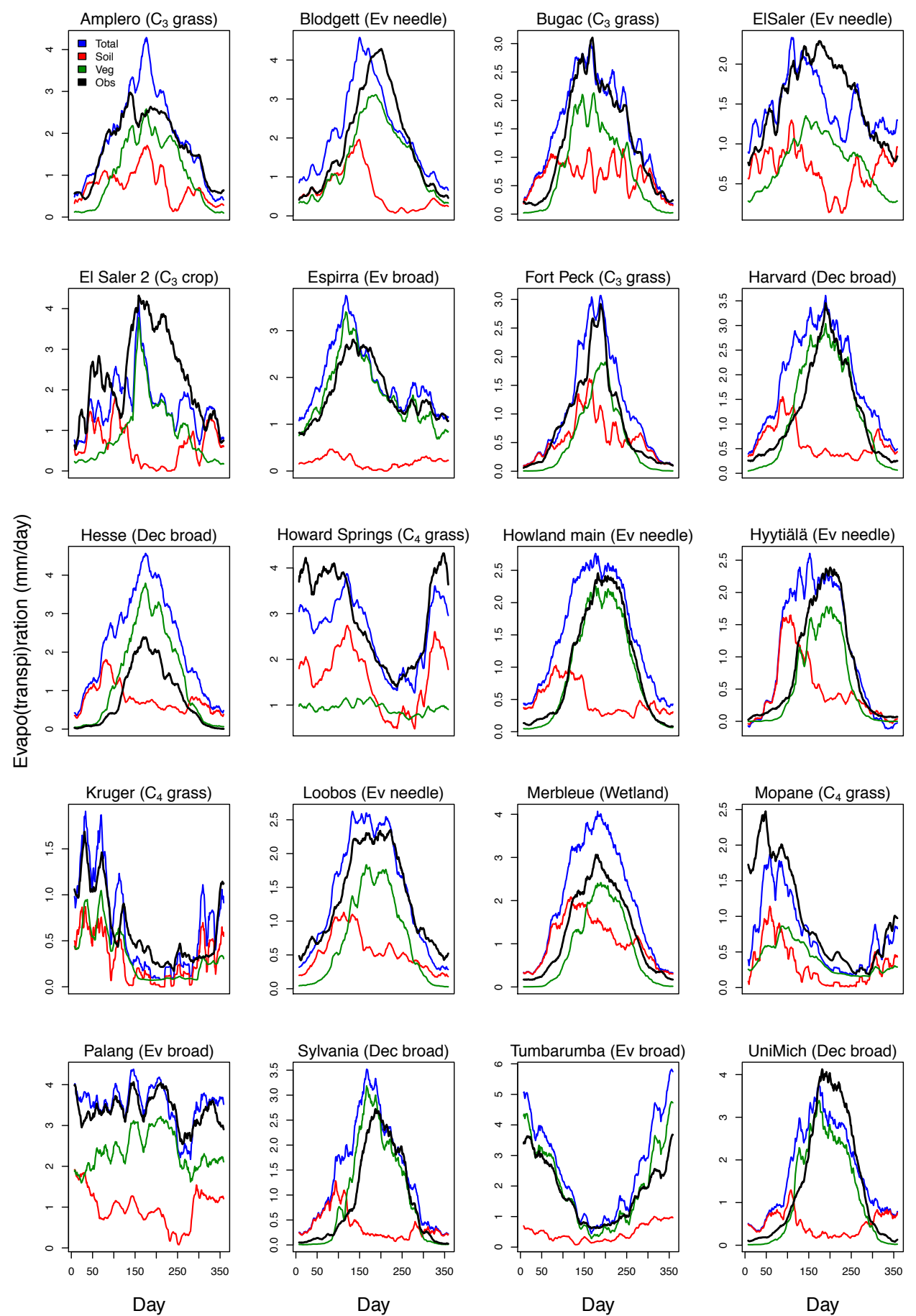

Fig. S7. 14-day running mean climatology of simulated total evapotranspiration (blue), soil evaporation (red) and transpiration (green). Observed total evapotranspiration (converted from $Q_{E}$ ) is shown in black. CABLE simulation using the new hydrology with Medlyn $g_{s}$, medium soil, centre LAI and $0^{\circ}$ slope was used for plotting. 


\section{References}

Clapp, R. B. and Hornberger, G. M.: Empirical equations for some soil hydraulic properties, Water Resour. Res., 14, 601-604, 1978. 